Article

\title{
Association of Yogurt Consumption with Nutrient Intakes, Nutrient Adequacy, and Diet Quality in American Children and Adults
}

\author{
Christopher J. Cifelli ${ }^{1, *(\mathbb{D}, \text { Sanjiv Agarwal }}{ }^{2}$ and Victor L. Fulgoni III ${ }^{3}$ (i) \\ 1 National Dairy Council, 10255 West Higgins Road, Suite 900, Rosemont, IL 60018-5616, USA \\ 2 NutriScience LLC, East Norriton, PA 19403, USA; agarwal47@yahoo.com \\ 3 Nutrition Impact, LLC, Battle Creek, MI 49014, USA; VIC3RD@aol.com \\ * Correspondence: Chris.Cifelli@dairy.org; Tel.: +1-847-627-3282
}

Received: 7 October 2020; Accepted: 2 November 2020; Published: 9 November 2020

\begin{abstract}
The popularity of yogurt has increased among consumers due to its perceived health benefits. This study examined the cross-sectional association between yogurt consumption and nutrient intake/adequacy, dietary quality, and body weight in children and adults. National Health and Nutrition Examination Survey 2001-2016 data $(n=65,799)$ were used and yogurt consumers were defined as those having any amount of yogurt during in-person 24-h diet recall. Usual intakes of nutrients were determined using the National Cancer Institute method and diet quality was calculated using the Healthy Eating Index-2015 (HEI-2015) scores after adjusting data for demographic and lifestyle factors. The data show that approximately $6.4 \%$ children and $5.5 \%$ adults consume yogurt, with a mean intake of yogurt of $150 \pm 3$ and $182 \pm 3 \mathrm{~g} / \mathrm{d}$, respectively. Yogurt consumers had higher diet quality (10.3\% and $15.2 \%$ higher HEI-2015 scores for children and adults, respectively); higher intakes of fiber, calcium, magnesium, potassium, and vitamin D; and higher percent of the population meeting recommended intakes for calcium, magnesium, and potassium than non-consumers. Consumption of yogurt was also associated with lower body weight, body mass index (BMI), and $23 \%$ showed a lower risk of being overweight/obese among adults only. In conclusion, yogurt consumption was associated with higher nutrient intake, nutrient adequacy, and diet quality in both children and adults.
\end{abstract}

Keywords: national health and nutrition examination survey; NHANES; healthy eating index; HEI; BMI; overweight; obese

\section{Introduction}

Fermented foods have played an important role in human health for centuries because of their enhanced preservation and functional properties [1]. The popularity of fermented foods has steadily increased among consumers because of their link to improved health. Yogurt is a semisolid fermented milk product produced by lactic acid-producing bacteria Lactobacillus bulgaricus and Streptococcus thermophilus [2]. Similar to other fermented foods, yogurt production has increased by over $4 \%$ between 1995 and 2019 [3] and, correspondingly, yogurt intake has steadily increased in the past decade [4]. Yogurt has higher amounts of protein, vitamin $\mathrm{B}_{2}$, vitamin $\mathrm{B}_{12}$, calcium, magnesium, potassium, and zinc than milk [5]. Yogurt may provide additional health benefits beyond nutrient provision because it contains unique bioactive compounds and live and active cultures [6].

An accumulating body of scientific evidence suggests that yogurt and fermented dairy consumption may be associated with improved cardiometabolic health [7-9]. Meta-analyses have shown that yogurt intake is linked with lower risk of type 2 diabetes [10,11], cardiovascular disease [12], metabolic syndrome [13], and with lower risk of cardiovascular- and all-cause mortality [14]. Higher yogurt 
consumption was associated with a $16 \%$ lower risk of high blood pressure in a long-term cohort study [15] and each additional serving of yogurt was associated with a $6 \%$ lower risk of incident hypertension in a Framingham Heart Study cohort [16]. Yogurt consumption has also been shown to be associated with a lower body mass index (BMI), lower body weight/weight gain, smaller waist circumference (WC), and lower body fat [17-20]. It has been hypothesized that the formation of unique bioactive compounds during fermentation, the presence of live and active cultures in fermented dairy, and conjugated linoleic acid of certain whole-milk yogurts are responsible for the beneficial associations between yogurt and cardiometabolic health $[7,8]$.

The relationship between yogurt consumption and nutrient adequacy and markers of cardiometabolic health has been previously investigated. Hobbs et al. [21] reported higher diet quality, nutrient intakes, and nutrient adequacy among British children consuming $>60 \mathrm{~g} / \mathrm{d}$ yogurt. Vatanparast et al. [22] also reported a higher nutrient intake and diet quality among Canadian children and adult yogurt consumers. Similarly, some studies have examined the possible links between yogurt consumption and nutrient adequacy and body weight in the US population. Wang et al. [23] reported that yogurt consumption was associated with better diet quality, higher nutrient intakes, and healthier metabolic profiles in adults from the Framingham Heart Study. Data from the National Health and Nutrition Examination Survey (NHANES) showed that yogurt was associated with higher nutrient intake, diet quality scores, and better metabolic profiles in children [24,25]. However, neither NHANES analysis examined the impact of yogurt consumption in adults.

Given the increase in popularity and consumption of yogurt in recent years, there is a need to more fully understand the impact of yogurt on health outcomes in both adults and children. Accordingly, the aim of the current study was to investigate the association between yogurt consumption, nutrient adequacy, diet quality, and body weight in American children and adults using the NHANES data set. We hypothesized that yogurt consumption would be associated with greater nutrient intakes/adequacy, improved diet quality, and lower body weight as compared to non-consumers.

\section{Materials and Methods}

\subsection{Subjects}

Food and nutrient data obtained from the dietary component of What We Eat In America (WWEIA) of NHANES 2001-2016 were used to assess yogurt intake [26]. NHANES is a continuous survey of a nationally representative sample of the non-institutionalized US population conducted by the National Center for Health Statistics (NCHS). The present analysis combined 8 NHANES datasets (NHANES 2001-2002, 2003-2004, 2005-2006, 2007-2008, 2009-2010, 2011-2012, 2013-2014, and 2015-2016). The combined sample included 65,799 participants aged 2 years and over, excluding pregnant females $(n=1356)$, lactating females $(n=338)$, and those with incomplete or unreliable 24-h recall data (8622). All participants provided written informed consent and the Research Ethics Review Board at the NCHS approved the survey protocol. The federal NHANES database, which is publicly available at [27], is exempt from approvals by Institutional Review Boards.

\subsection{Estimation of Energy and Nutrients Intakes}

Dietary intake data with reliable 24-h recall dietary interviews using the United States Department of Agriculture's (USDA) automated multiple-pass method were used [28]. The 24-h recall data for each participant in these surveys includes a description of the individual foods and beverages consumed on the previous day (midnight to midnight) and the amount by weight. Complete descriptions of the dietary interview methods for NHANES are provided elsewhere [26]. Yogurt was defined as $\mathrm{g}$ of food in "USDA food subgroup 18" and includes both plain and flavored, Greek and regular, and all fat varieties of yogurt. [29]. Yogurt consumers were defined as those consuming any amount of yogurt during the first (in-person) 24-h recall. Participants were dichotomized into consumers and non-consumers of yogurt. The second dietary recall was used to assess usual nutrient intakes. 
Energy and nutrients for each food and beverage consumed were determined using the NHANES cycle specific the USDA Food and Nutrient Database for Dietary Studies (FNDDS) [29]. In our analysis, intake of calcium, iron, magnesium, potassium, thiamin, folate, and vitamins $A_{1}, B_{6}, B_{12}, C$, and D was analyzed as these are defined as "under consumed nutrients" by the Dietary Guidelines for Americans 2015-2020 (DGA) [30].

\subsection{Estimation of Diet Quality and Intake of Food Groups}

Diet quality scores were determined using the USDA Healthy Eating Index-2015 (HEI-2015) [31]. The HEI-2015 contains 13 subcomponents, each reflecting the DGA's recommendations. HEI-2015 scores were estimated using day 1 dietary intake data. Dietary intake was expressed per $1000 \mathrm{kcal}$ for all components except for fatty acid ratios (expressed as a ratio of unsaturated to saturated fatty acids), saturated fat (expressed as \% energy), and added sugars (expressed as \% energy). Total vegetables; greens and beans; total fruit, whole fruit; total protein; and seafoods and plant proteins were scored proportionally from 0 to 5 points and all other components (i.e., whole grains; dairy; fatty acids; sodium; refined grains; saturated fat; and added sugars) were scored proportionally from 0 to 10 points. The maximum possible score was 100 [31].

The USDA Food Patterns Equivalents Database (FPED) [32] was used to calculate an intake of MyPlate [33] servings (MyPyramid Equivalents Database was used for 2001-2004 data). The number of MyPlate servings was aggregated over all foods consumed during the 24-h recall to calculate the MyPlate food group intakes per day.

\subsection{Estimation of Anthropometric Measures}

Body weight, waist circumference, body mass index (BMI) for adults, and BMI z-score for children were calculated using NHANES standard protocols and using the Statistical Analysis Software program for CDC and Prevention's Growth Charts [26,34]. In adults overweight or obese the BMI was defined as $\geq 25 \mathrm{~kg} / \mathrm{m}^{2}$ and the elevated waist circumference was defined as $>102 \mathrm{~cm}$ for males and $>88 \mathrm{~cm}$ for females [35]. Children with BMI z-scores between the 85th and $<95$ th percentile were considered overweight, and those with BMI z-scores in the $\geq 95$ th percentile were considered obese [34].

\subsection{Statistical Analysis}

All analyses were performed using SAS 9.4 (SAS Institute, Cary, NC, USA) software. The data were adjusted for the complex sampling design of NHANES, using appropriate survey weights, strata, and primary sampling units. Day one dietary/examination weights were used in all intake analysis and Mobile Examination Center weights were used for anthropometric variables.

Least square means (LSM) and standard errors (SE) were generated for energy and nutrient intake, food group intake, diet quality, and anthropometric variables in yogurt consumers and non-consumers via regression analyses. Analyses were adjusted for age, gender, ethnicity, poverty income ratio, physical activity level, current smoking status, and alcohol (only for those 19 years and older), and kcal (except for energy and HEI-2015). Usual intakes of nutrients were determined using the National Cancer Institute (NCI) method [36] and the NCI macros (Mixtran and Distrib) were used to generate parameter effects after covariate adjustments and to estimate the distribution of usual intake (UI). The one-part NCI model was used for nutrients since these substances are consumed on most days by most subjects. Covariates for usual intake estimation included day of the week of the 24-h recall [coded as weekend (Friday-Sunday) or weekday (Monday-Thursday)] and sequence of dietary recall (first or second), and variance estimates were obtained using the two days of intake with one-day sampling weights. The percentage of the population below the Estimated Average Requirement (EAR) or above Adequate Intake (AI) of nutrients was assessed using the cut-point method (except for iron where the probability method was used) and Z-statistic was used to assess differences between non-consumers and yogurt consumers. Logistic regression was utilized to assess the association of yogurt consumption with risk of overweight/obesity in children and adults. $p<0.01$ was considered statistically significant. 


\section{Results}

\subsection{Yogurt Intake}

Approximately $6.4 \%$ of children and $5.5 \%$ of adults consume yogurt. Yogurt consumers were 3.0 and 2.6 years younger than non-consumers in children and adults, respectively. While in children a similar percentage of males/females consume yogurt, a smaller percentage of adult males consume yogurt. A greater percentage of yogurt consumers were non-Hispanic White (and a lower percentage yogurt consumer were non-Hispanic Blacks) as compared to non-consumers in both children and adults. A greater percentage of yogurt consumers had a household income $>1.85$ the poverty level and a lower percentage yogurt consumer had a household income $<1.35$ the poverty level as compared to non-consumers in both children and adults (Supplementary Table S1). The mean intake of yogurt (on day 1 of recall) among consumers was $150 \pm 3 \mathrm{~g} / \mathrm{d}$ (95th percentile $307 \mathrm{~g} / \mathrm{d}$ ) and $182 \pm 3 \mathrm{~g} / \mathrm{d}$ (95th percentile $337 \mathrm{~g} / \mathrm{d}$ ) among children and adults, respectively. Median intake was $122 \mathrm{~g} / \mathrm{d}$ in children and $169 \mathrm{~g} / \mathrm{d}$ in adults. Mean per capita intake of yogurt (on day 1 of recall) was $11.6 \pm 0.5$ and $12.9 \pm 0.5 \mathrm{~g} / \mathrm{day}$ among children and adults, respectively, and has significantly increased ( $\beta=0.59 \mathrm{~g} / \mathrm{cycle}, p=0.0164$ for children; $\beta=1.46$, g/cycle $p<0.0001$ for adults) over the last eight NHANES cycles (2001-2016).

Yogurt provided on average $7.7 \%$ of energy, $18.5 \%$ of calcium, $10.5 \%$ of vitamin $\mathrm{D}, 12.3 \%$ of potassium, $14.3 \%$ of vitamin $\mathrm{B}_{12}, 10.4 \%$ of protein, $16.9 \%$ of total sugars, and $17.9 \%$ of added sugars in children (Table 1). Similar results were observed in adults where, on average, yogurt provided $7.6 \%$ of energy, $21.7 \%$ of calcium, $15.5 \%$ of vitamin $\mathrm{D}, 11.2 \%$ of potassium, $15.6 \%$ of vitamin $\mathrm{B}_{12}, 11.0 \%$ of protein, $17.5 \%$ of total sugars, and $16.3 \%$ of added sugars (Table 1 ).

Table 1. Energy and nutrient intakes in children and adult yogurt consumers from all sources and from yogurt only (National Health and Nutrition Examination Survey (NHANES) 2001-2016, gender combined data).

\begin{tabular}{|c|c|c|c|c|}
\hline \multirow[t]{2}{*}{ Variable } & \multicolumn{2}{|c|}{ Children (2-18 Years) } & \multicolumn{2}{|c|}{ Adults ( $\geq 19$ Years) } \\
\hline & All sources & Yogurt only & All sources & Yogurt only \\
\hline Energy (kcal) & $1860 \pm 25$ & $144 \pm 3$ & $2114 \pm 25$ & $160 \pm 2$ \\
\hline Carbohydrate (g) & $257 \pm 3$ & $24.6 \pm 0.6$ & $267 \pm 4$ & $25.7 \pm 0.5$ \\
\hline Dietary fiber $(\mathrm{g})$ & $13.5 \pm 0.2$ & $0.08 \pm 0.01$ & $19.8 \pm 0.3$ & $0.24 \pm 0.02$ \\
\hline Total sugars (g) & $137 \pm 2$ & $23.2 \pm 0.6$ & $126 \pm 2$ & $22.0 \pm 0.5$ \\
\hline Added sugars (tsp eq) & $17.6 \pm 0.4$ & $3.15 \pm 0.09$ & $16.3 \pm 0.4$ & $2.65 \pm 0.09$ \\
\hline Protein $(\mathrm{g})$ & $67.9 \pm 1.2$ & $7.07 \pm 0.16$ & $87.4 \pm 1.2$ & $9.59 \pm 0.20$ \\
\hline Total fat (g) & $65.0 \pm 1.3$ & $2.15 \pm 0.07$ & $76.3 \pm 1.2$ & $2.25 \pm 0.07$ \\
\hline Cholesterol (mg) & $198 \pm 8$ & $8.0 \pm 0.2$ & $249 \pm 6$ & $9.28 \pm 0.22$ \\
\hline Calcium (mg) & $1227 \pm 22$ & $227 \pm 5$ & $1228 \pm 17$ & $267 \pm 4$ \\
\hline Iron (mg) & $13.3 \pm 0.3$ & $0.12 \pm 0.003$ & $15.6 \pm 0.3$ & $0.16 \pm 0.004$ \\
\hline Magnesium (mg) & $246 \pm 3$ & $22.4 \pm 0.5$ & $351 \pm 5$ & $26.9 \pm 0.4$ \\
\hline Potassium (mg) & $2383 \pm 35$ & $294 \pm 6$ & $3133 \pm 38$ & $350 \pm 5$ \\
\hline Sodium (mg) & $2719 \pm 45$ & $87.5 \pm 1.8$ & $3373 \pm 47$ & $103 \pm 2$ \\
\hline Vitamin A, RAE $(\mu \mathrm{g})$ & $639 \pm 16$ & $29.5 \pm 2.0$ & $749 \pm 17$ & $48.7 \pm 2.2$ \\
\hline Thiamin (mg) & $1.47 \pm 0.02$ & $0.06 \pm 0.001$ & $1.69 \pm 0.03$ & $0.07 \pm 0.001$ \\
\hline Folate, DFE $(\mu \mathrm{g})$ & $521 \pm 13$ & $14.7 \pm 0.4$ & $600 \pm 12$ & $18.7 \pm 0.4$ \\
\hline Vitamin $\mathrm{B}_{6}(\mathrm{mg})$ & $1.61 \pm 0.03$ & $0.06 \pm 0.001$ & $2.20 \pm 0.05$ & $0.08 \pm 0.001$ \\
\hline Vitamin $B_{12}(\mu g)$ & $5.12 \pm 0.12$ & $0.73 \pm 0.01$ & $5.88 \pm 0.21$ & $0.92 \pm 0.01$ \\
\hline Vitamin C (mg) & $84.6 \pm 3.0$ & $1.45 \pm 0.09$ & $102 \pm 3$ & $2.43 \pm 0.14$ \\
\hline Vitamin D $(\mu \mathrm{g})$ & $6.57 \pm 0.18$ & $0.69 \pm 0.03$ & $5.41 \pm 0.17$ & $0.84 \pm 0.03$ \\
\hline
\end{tabular}

Values are weighted means \pm standard error of means. RAE, retinol activity equivalents; DFE, dietary folate equivalent. 


\subsection{Comparison Between Yogurt Consumers vs. Non-Consumers on Energy and Nutrient Intakes}

There were significant differences in nutrient intake between yogurt consumers and non-consumers (Table 2). In children, yogurt consumers had higher intakes of carbohydrate (2.3\%), dietary fiber $(4.5 \%)$, total sugars $(9.3 \%)$, protein $(4.9 \%)$, calcium $(21.4 \%)$, magnesium $(10.0 \%)$, potassium $(11.1 \%)$, vitamin $\mathrm{B}_{12}(7.1 \%)$, and vitamin $\mathrm{D}(7.6 \%)$, as well as lower intakes of total fat $(-5.2 \%)$, and sodium $(-5.7 \%)$ than non-consumers ( $p<0.01$ for all). Similarly, adult yogurt consumers had higher intakes of energy $(4.9 \%)$, carbohydrate $(4.7 \%)$, dietary fiber $(15.9 \%)$, total sugars $(9.6 \%)$, protein $(7.0 \%)$, calcium (30.3\%), magnesium (17.1\%), potassium (15.3\%), vitamin A $(11.5 \%)$, folate $(9.8 \%)$, vitamin $\mathrm{B}_{6}(8.9 \%)$, vitamin $\mathrm{B}_{12}(13.5 \%)$, vitamin $\mathrm{C}(19.2 \%)$, and vitamin $\mathrm{D}(13.7 \%)$, as well as lower intakes of added sugars $(-6.7 \%)$, total fat $(-8.5 \%)$, cholesterol $(-12.5 \%)$. and sodium $(-6.3 \%)$ than non-consumers $(p<0.01$ for all). The intake of other nutrients was not significantly different among yogurt consumers and non-consumers (Table 2).

Table 2. Covariate adjusted energy and nutrient intakes in children and adult yogurt consumers and non-consumers (NHANES 2001-2016, gender combined data).

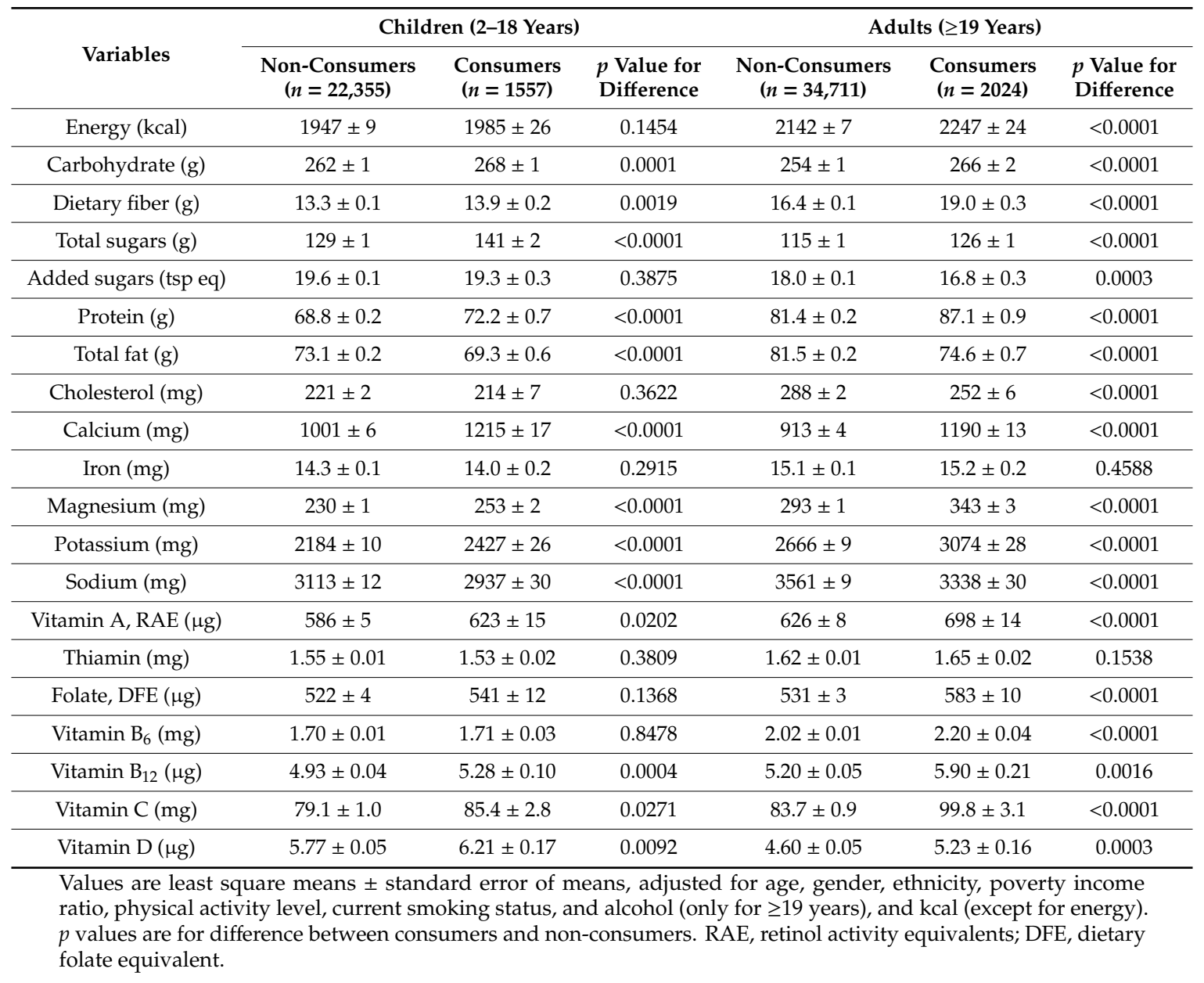

A lower proportion of yogurt consumers compared to non-consumers $(p<0.01)$ were below the EAR for six nutrients for children and four nutrients for adults out of the 10 nutrients examined. Yogurt consumers had at least a 10 percentage unit difference in the population below the EAR for calcium $(-33.2 \%$ and $-27.6 \%$ for children and adults, respectively), magnesium $(-22.8 \%$ and $-25.4 \%$ for children and adults, respectively), and vitamin A (-18.6\% for both children and adults) when compared to non-consumers. The percentage above the AI for fiber among adults and for potassium for both children and adults were higher $(p<0.0001)$ among yogurt consumers compared to non-consumers (Table 3). 
Table 3. Nutrient adequacy in children and adult yogurt consumers and non-consumers (NHANES 2001-2016, gender combined data).

\begin{tabular}{|c|c|c|c|c|c|c|}
\hline \multirow{2}{*}{ Variables } & \multicolumn{3}{|c|}{ Children (2-18 Years) } & \multicolumn{3}{|c|}{ Adults ( $\geq 19$ Years) } \\
\hline & $\begin{array}{l}\text { Non-Consumers } \\
\quad(n=24,322)\end{array}$ & $\begin{array}{l}\text { Consumers } \\
(n=1676)\end{array}$ & $\begin{array}{l}p \text { Value for } \\
\text { Difference }\end{array}$ & $\begin{array}{l}\text { Non-Consumers } \\
(n=37,598)\end{array}$ & $\begin{array}{l}\text { Consumers } \\
(n=2200)\end{array}$ & $\begin{array}{l}p \text { Value for } \\
\text { Difference }\end{array}$ \\
\hline & \multicolumn{6}{|c|}{$\%$ population below Estimated Average Requirement (EAR) } \\
\hline Calcium (mg) & $48.6 \pm 0.7$ & $15.4 \pm 1.9$ & $<0.0001$ & $48.3 \pm 0.6$ & $20.7 \pm 1.7$ & $<0.0001$ \\
\hline Iron (mg) & $2.18 \pm 0.13$ & $1.57 \pm 0.47$ & 0.0770 & $5.01 \pm 0.12$ & $5.51 \pm 0.61$ & 0.3147 \\
\hline Magnesium (mg) & $37.0 \pm 0.6$ & $14.2 \pm 1.0$ & $<0.0001$ & $58.0 \pm 0.7$ & $32.6 \pm 1.5$ & $<0.0001$ \\
\hline Vitamin A, RAE ( $\mu \mathrm{g})$ & $26.2 \pm 0.9$ & $7.58 \pm 1.60$ & $<0.0001$ & $48.1 \pm 0.8$ & $29.5 \pm 2.1$ & 0.0004 \\
\hline Thiamin (mg) & $1.34 \pm 0.20$ & $0.56 \pm 0.27$ & 0.0045 & $7.04 \pm 0.41$ & $5.47 \pm 1.20$ & 0.3987 \\
\hline Folate, DFE $(\mu \mathrm{g})$ & $3.82 \pm 0.43$ & $0.82 \pm 0.52$ & $<0.0001$ & $12.3 \pm 0.5$ & $9.34 \pm 1.57$ & 0.3099 \\
\hline Vitamin $\mathrm{B}_{6}(\mathrm{mg})$ & $2.18 \pm 0.32$ & $1.25 \pm 0.51$ & 0.1048 & $12.9 \pm 0.6$ & $10.9 \pm 1.4$ & 0.4282 \\
\hline Vitamin $B_{12}(\mu \mathrm{g})$ & $0.86 \pm 0.15$ & $0.11 \pm 0.08$ & $<0.0001$ & $4.35 \pm 0.33$ & $0.76 \pm 0.40$ & $<0.0001$ \\
\hline Vitamin C (mg) & $19.2 \pm 0.9$ & $9.39 \pm 1.87$ & 0.0240 & $45.1 \pm 0.8$ & $34.8 \pm 1.8$ & 0.0138 \\
\hline \multirow[t]{2}{*}{ Vitamin D ( $\mu \mathrm{g})$} & $91.1 \pm 0.5$ & $86.4 \pm 2.0$ & 0.3103 & $95.4 \pm 0.3$ & $93.2 \pm 1.5$ & 0.3487 \\
\hline & \multicolumn{6}{|c|}{$\%$ population above Adequate Intake (AI) } \\
\hline Dietary fiber (g) & $0.62 \pm 0.08$ & $2.03 \pm 0.71$ & 0.0158 & $5.81 \pm 0.29$ & $16.8 \pm 1.2$ & $<0.0001$ \\
\hline Potassium (mg) & $33.2 \pm 0.8$ & $53.1 \pm 2.0$ & $<0.0001$ & $31.3 \pm 0.6$ & $57.3 \pm 1.6$ & $<0.0001$ \\
\hline Sodium (mg) & $99.9 \pm 0.03$ & $99.9 \pm 0.1$ & 0.1421 & $99.2 \pm 0.1$ & $99.2 \pm 0.4$ & 0.9242 \\
\hline
\end{tabular}

Values are means \pm standard error of means. $p$ values are for difference between consumers and non-consumers. RAE, retinol activity equivalents; DFE, dietary folate equivalent.

\subsection{Link Between Yogurt Intake and Diet Quality}

Intake of yogurt was associated with $10.3 \%$ and $15.1 \%$ higher HEI-2015 scores $(p<0.01)$ in children and adults, respectively (Table 4). The HEI-2015 subcomponent scores for 'greens and beans,' 'total fruit,' 'whole fruit,' 'whole grain,' 'dairy,' 'seafood and plant protein,' 'sodium,' 'refined grains,' and 'saturated fat' were higher $(\mathrm{p}<0.01)$ in consumers compared to non-consumers for both children and adults. Additionally, adult yogurt consumers had a higher score for 'added sugar' and a lower score for 'fatty acids ratios' ( $p<0.01$ for all).

Intake of yogurt was also linked with significant differences $(p<0.01)$ in specific MyPlate food groups [33]. Yogurt consumers compared to non-consumers had higher intakes of total dairy $(+21.9 \%$ in children; $+38.7 \%$ in adults), total fruit $(+26.7 \%$ in children; $+49.5 \%$ in adults), whole fruit $(+36.7 \%$ in children; $+66.7 \%$ in adults), and whole grain $(+25.4 \%$ in children; $+44.3 \%$ in adults) (Figure 1$)$. 
Table 4. Healthy Eating Index (HEI)-2015 scores for children and adult yogurt consumers and non-consumers. (NHANES 2001-2016, gender combined data).

\begin{tabular}{|c|c|c|c|c|c|c|c|c|}
\hline & \multicolumn{4}{|c|}{ Children (2-18 Years) } & \multicolumn{4}{|c|}{ Adults ( $\geq 19$ Years) } \\
\hline & $\begin{array}{c}\text { Non-Consumers } \\
(n=22,335)\end{array}$ & $\begin{array}{l}\text { Consumers } \\
(n=1557)\end{array}$ & $\beta$ & $\begin{array}{l}p \text { Value for } \\
\text { Difference }\end{array}$ & $\begin{array}{c}\text { Non-Consumers } \\
\quad(n=34,711)\end{array}$ & $\begin{array}{l}\text { Consumers } \\
(n=2024)\end{array}$ & $\beta$ & $\begin{array}{l}p \text { Value for } \\
\text { Difference }\end{array}$ \\
\hline HEI-2015 total score & $46.6 \pm 0.2$ & $51.4 \pm 0.5$ & $4.8 \pm 0.5$ & $<0.0001$ & $50.2 \pm 0.1$ & $57.8 \pm 0.4$ & $7.6 \pm 0.4$ & $<0.0001$ \\
\hline $\begin{array}{c}\text { Component } 1 \\
\text { (total vegetables) }\end{array}$ & $2.16 \pm 0.02$ & $2.05 \pm 0.05$ & $-0.12 \pm 0.06$ & 0.0419 & $3.11 \pm 0.01$ & $3.10 \pm 0.04$ & $-0.01 \pm 0.04$ & 0.7977 \\
\hline $\begin{array}{c}\text { Component } 2 \\
\text { (greens and beans) }\end{array}$ & $0.83 \pm 0.02$ & $1.02 \pm 0.07$ & $0.19 \pm 0.07$ & 0.0082 & $1.46 \pm 0.02$ & $1.79 \pm 0.06$ & $0.33 \pm 0.06$ & $<0.0001$ \\
\hline $\begin{array}{c}\text { Component } 3 \\
\text { (total fruit) }\end{array}$ & $2.45 \pm 0.03$ & $2.99 \pm 0.08$ & $0.54 \pm 0.08$ & $<0.0001$ & $2.06 \pm 0.02$ & $2.88 \pm 0.06$ & $0.82 \pm 0.06$ & $<0.0001$ \\
\hline $\begin{array}{l}\text { Component } 4 \\
\text { (whole fruit) }\end{array}$ & $2.12 \pm 0.03$ & $2.85 \pm 0.08$ & $0.73 \pm 0.08$ & $<0.0001$ & $2.01 \pm 0.02$ & $3.05 \pm 0.06$ & $1.04 \pm 0.06$ & $<0.0001$ \\
\hline $\begin{array}{l}\text { Component } 5 \\
\text { (whole grains) }\end{array}$ & $2.14 \pm 0.04$ & $2.55 \pm 0.14$ & $0.41 \pm 0.14$ & 0.0043 & $2.38 \pm 0.03$ & $3.29 \pm 0.11$ & $0.91 \pm 0.11$ & $<0.0001$ \\
\hline $\begin{array}{l}\text { Component } 6 \\
\text { (dairy) }\end{array}$ & $6.89 \pm 0.04$ & $8.09 \pm 0.10$ & $1.20 \pm 0.10$ & $<0.0001$ & $4.95 \pm 0.03$ & $6.93 \pm 0.07$ & $1.98 \pm 0.07$ & $<0.0001$ \\
\hline $\begin{array}{c}\text { Component } 7 \\
\text { (total protein foods) }\end{array}$ & $3.55 \pm 0.02$ & $3.40 \pm 0.06$ & $-0.15 \pm 0.06$ & 0.0137 & $4.20 \pm 0.01$ & $4.20 \pm 0.04$ & $-0.00 \pm 0.04$ & 0.9635 \\
\hline $\begin{array}{c}\text { Component } 8 \\
\text { (seafood and plant } \\
\text { protein) }\end{array}$ & $1.53 \pm 0.02$ & $1.86 \pm 0.10$ & $0.33 \pm 0.10$ & 0.0009 & $2.25 \pm 0.02$ & $2.74 \pm 0.07$ & $0.49 \pm 0.11$ & $<0.0001$ \\
\hline $\begin{array}{c}\text { Component } 9 \\
\text { (fatty acid ratio) }\end{array}$ & $3.82 \pm 0.04$ & $3.51 \pm 0.15$ & $-0.31 \pm 0.15$ & 0.0442 & $5.02 \pm 0.03$ & $4.70 \pm 0.11$ & $-0.32 \pm 0.11$ & 0.0053 \\
\hline $\begin{array}{l}\text { Component } 10 \\
\text { (sodium) }\end{array}$ & $4.91 \pm 0.04$ & $5.69 \pm 0.13$ & $0.78 \pm 0.13$ & $<0.0001$ & $4.16 \pm 0.03$ & $4.91 \pm 0.10$ & $0.75 \pm 0.11$ & $<0.0001$ \\
\hline $\begin{array}{l}\text { Component } 11 \\
\text { (refined grain) }\end{array}$ & $5.20 \pm 0.04$ & $5.96 \pm 0.13$ & $0.76 \pm 0.13$ & $<0.0001$ & $6.15 \pm 0.03$ & $7.03 \pm 0.10$ & $0.88 \pm 0.10$ & $<0.0001$ \\
\hline $\begin{array}{l}\text { Component } 12 \\
\text { (saturated fat) }\end{array}$ & $5.49 \pm 0.04$ & $5.92 \pm 0.15$ & $0.43 \pm 0.16$ & 0.0084 & $5.97 \pm 0.03$ & $6.46 \pm 0.10$ & $0.49 \pm 0.10$ & $<0.0001$ \\
\hline $\begin{array}{l}\text { Component } 13 \\
\text { (added sugar) }\end{array}$ & $5.52 \pm 0.04$ & $5.51 \pm 0.11$ & $-0.01 \pm 0.11$ & 0.9766 & $6.51 \pm 0.04$ & $6.78 \pm 0.09$ & $0.27 \pm 0.09$ & 0.0036 \\
\hline
\end{tabular}

Values are least square means \pm standard error of means, adjusted for age, gender, ethnicity, poverty income ratio, physical activity level, and current smoking status and alcohol (only for $\geq 19$ years). $p$ values are for difference between consumers and non-consumers. $\beta$ is the difference between consumers and non-consumers. 


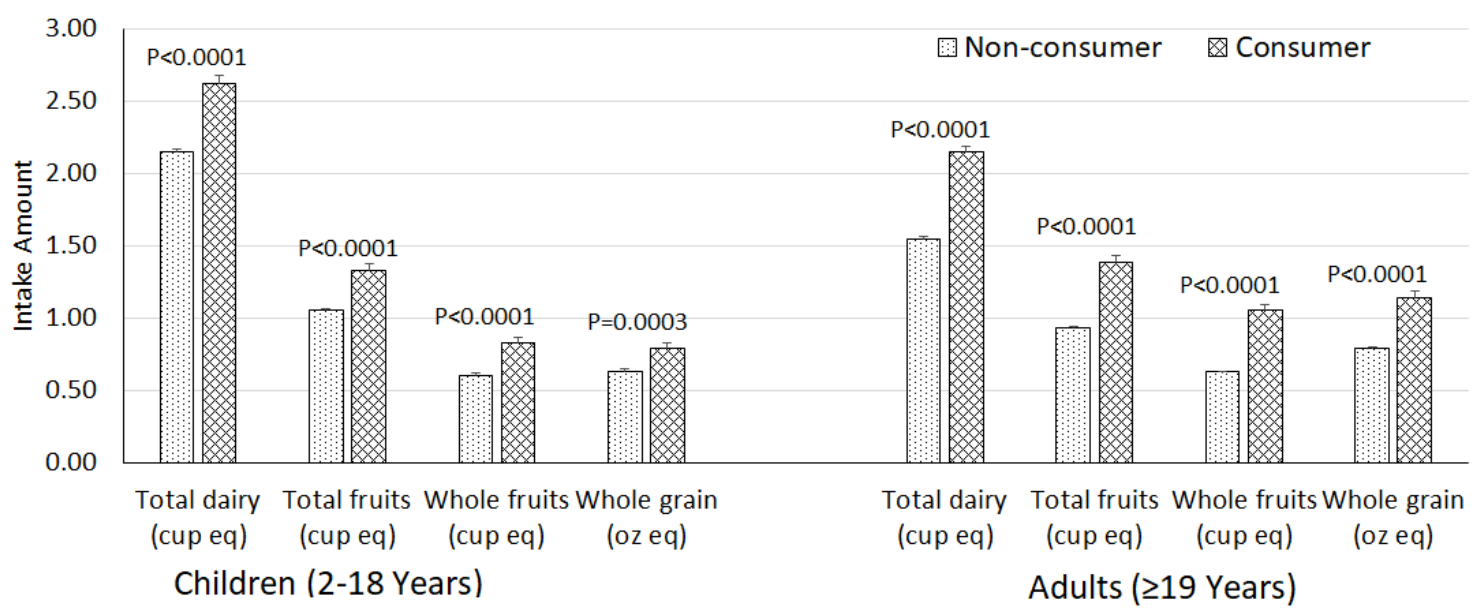

Figure 1. Covariate-adjusted select food groups intakes in children and adult yogurt consumers and non-consumers (NHANES 2001-2016, gender combined data). Values are least square means \pm standard error of means, adjusted for age, gender, ethnicity, poverty income ratio, physical activity level, current smoking status, and alcohol (only for $\geq 19$ years), and kcal. $p$ values are for difference between consumers and non-consumers.

\subsection{Association Between Yogurt Intake and Anthropometric Measures}

Anthropometric data are presented in Table 5. Yogurt consumption was inversely associated with BMI $\left(-0.9 \mathrm{~kg} / \mathrm{m}^{2}, p<0.0001\right)$, body weight $(-2.1 \mathrm{~kg}, p=0.0004)$, and waist circumference $(-2.3 \mathrm{~cm}$, $p<0.0001)$ among adults. Furthermore, among adults, yogurt consumers had a $23 \%$ lower risk of being overweight or obese (OR: $0.77 ; 99 \%$ CI: $0.65,0.91 ; p=0.0001$ ) and a $29 \%$ lower risk of having an elevated waist circumference (OR: $0.71 ; 99 \%$ CI: 0.60, 0.85; $p<0.0001$ ) compared to non-consumers. There were no differences in anthropometric measures between yogurt consumers and non-consumers in children.

Table 5. Association of yogurt consumption with anthropometric measures in children and adults.

(NHANES 2001-2016, gender combined data).

\begin{tabular}{ccccc}
\hline Variables & Non-Consumer & \multicolumn{2}{c}{ Consumer } & \multirow{2}{*}{$\begin{array}{c}\text { Value for } \\
\text { Difference }\end{array}$} \\
\cline { 2 - 3 } & $\boldsymbol{n}$ LSM \pm SEM & $n$ & LSM \pm SEM & \\
\hline Children (2-18 years) & & & & \\
\hline BMI z-Score & $21,9490.49 \pm 0.02$ & 1520 & $0.43 \pm 0.04$ & 0.2140 \\
\hline Weight $(\mathrm{kg})$ & $22,10043.0 \pm 0.2$ & 1536 & $42.2 \pm 0.4$ & 0.0311 \\
\hline Waist Circumference $(\mathrm{cm})$ & $21,61568.9 \pm 0.2$ & 1456 & $68.1 \pm 0.4$ & 0.0635 \\
\hline Adults $(\geq 19$ years) & & & & \\
\hline BMI $\left(\mathrm{kg} / \mathrm{m}^{2}\right)$ & $34,13328.8 \pm 0.1$ & 1995 & $27.9 \pm 0.2$ & $<0.0001$ \\
\hline Weight $(\mathrm{kg})$ & $34,27482.4 \pm 0.2$ & 1998 & $80.3 \pm 0.6$ & 0.0004 \\
\hline Waist Circumference $(\mathrm{cm})$ & $33,41698.8 \pm 0.2$ & 1947 & $96.5 \pm 0.5$ & $<0.0001$ \\
\hline
\end{tabular}

Values are adjusted for age, gender, ethnicity, poverty income ratio, physical activity level, current smoking status and alcohol (only for 19 years and older), and kcal. $p$ values are for difference between consumers and non-consumers. LSM, least square means; SEM, standard error of means; BMI, body mass index.

\section{Discussion}

This is the first report to investigate the association between yogurt consumption and nutrient intakes, nutrient adequacy, diet quality, and weight status in a nationally representative population of American children and adults. Combining data from eight cycles of NHANES, the present analysis showed that yogurt consumption was associated with higher nutrient intakes and better nutrient 
adequacy, as well as a higher diet quality score compared with non-consumers for both children and adults. Furthermore, weight-related outcomes were better in adult yogurt consumers when compared to non-consumers.

Approximately $6 \%$ of Americans consumed yogurt on day 1 of the NHANES 24-h dietary recall. The prevalence of yogurt consumption in American children and adults in the present analysis is less than recent estimates in British and Canadian population groups [21,22]. Using data from the National Diet and Nutrition Survey, Hobbs et al. [21] reported that about $62 \%$ of children aged $4-10$ years and $31 \%$ of children aged 11-18 years were yogurt consumers. Similarly, Vatanparast et al. [22] analyzed data from Canadian Community Health Survey 2015 and found 20\% Canadians consumed yogurt on a given day. The prevalence of yogurt consumption observed in this study is close to those by Keast et al. [25], who estimated that $8.5 \%$ of children and adolescents age 8-11 years were yogurt based on data from NHANES 2005-2008. Other estimates indicated that 33\% children age 2-18 years (NHANES 2003-2006), and $41 \%$ men and 64\% women (Framingham Heart Study Cohorts 1998-2001, 2002-2005) consumed yogurt at least once per week [23,24]. While the prevalence observed in our analysis appears low, on a population basis this represents about 12 million individuals. The mean intake of yogurt in this study are higher than the $135 \mathrm{~g} / \mathrm{d}$ intake estimate for the Canadian population [22] and a $108 \mathrm{~g} / \mathrm{d}$ intake tertile II estimate for 8-11-year-old British children [21]. In this analysis, the mean intake of yogurt among consumers was 5.3 fluid oz/d (0.66 cups or $162 \mathrm{~g}$ ) for children and 6.4 fluid oz/d ( 0.8 cups or $196 \mathrm{~g}$ ) for adults, which represents approximately 0.9 servings per day for children and 1.1 servings per day for adults. Thus, regular yogurt consumption may significantly contribute to meeting the DGA recommendations for dairy foods.

Yogurt consumers had significantly higher intakes of fiber, calcium, magnesium, potassium, vitamin $A$, vitamin $B_{6}$, vitamin $B_{12}$, vitamin $C$, and vitamin $D$ than non-consumers. Along those lines, yogurt consumers also had a higher nutrient adequacy for fiber, calcium, magnesium, potassium, vitamin $A$, and vitamin $B_{12}$ than non-consumers. Many of these nutrients are currently under-consumed by Americans and have been identified as "shortfall nutrients" by the DGA [30]. Additionally, the DGA has classified dietary fiber, calcium, potassium, and vitamin D as "nutrients of public health concern" because their current intakes are low enough to impact one's health [30]. Similar observations were also reported in earlier cross-sectional studies from both US and international cohorts [21-25]. Since yogurt is a good source of several of the above nutrients [37-41], yogurt consumption is naturally expected to lead to more nutrient dense diets and greater adequacy for nutrients. Finally, children and adult consumers of yogurt compared to non-consumers had 176 and $223 \mathrm{mg} / \mathrm{d}$ lower intakes of sodium respectively. High sodium intake has been linked to elevated blood pressure and therefore reducing dietary sodium is an important target for public health improvement [30].

As yogurt is not a good source of fiber and vitamin C, the results suggest that yogurt consumers are eating higher amounts of other healthy foods as well. Indeed, this was reflected in the fact that both children and adult yogurt consumers had better diet quality scores than non-consumers. Diet quality was assessed by HEI-2015 [31] in the present analysis. HEI is a validated measure of diet quality and is indicative of compliance/adherence of a person's diet to the eating pattern recommended by the DGA [30]. HEI is commonly used to evaluate diets in population groups [42], food environments [43], to assess changes in the diet quality over time [44], and to validate other nutrition research tools and indexes [45]. It has also been used in recent research to understand relationships between nutrients/foods/dietary patterns and health-related outcomes [46-49]. In the present analysis, HEI-2015 total scores of yogurt consumers were significantly higher for children and adults than their respective non-consumers, indicating a higher compliance to nutritional guidelines. These results are consistent with earlier cross-sectional analyses, which found that yogurt consumers have a significantly higher diet quality than non-consumers [21-25]. HEI-2015 has 13 subcomponents (nine for adequacy and four for moderation) [31] and the scores for 9 and 10 subcomponents were also significantly higher for children and adult consumers. It is interesting to note that not only were the HEI-2015 subcomponent scores related to dairy, fruits, vegetables, and whole grain higher, the actual intakes of these food 
groups were also significantly higher in yogurt consumers than non-consumers. This is important because current intakes of these food groups are lower than the recommended amounts in the USDA's Healthy US-Style Eating Pattern [30]. Indeed, the majority of the US population currently does not meet the daily intake recommendations for fruits (nearly $80 \%$ ), vegetables (nearly $90 \%$ ), whole grain (nearly 100\%), and dairy (nearly $80 \%$ ) [37].

In the current study, adult yogurt consumers had a lower weight, BMI, and waist circumference than non-consumers and yogurt consumption was significantly associated with lower odds of being overweight or obese and having an elevated waist circumference. This is an interesting finding since adult yogurt consumers also had about a $5 \%$ higher calorie intake. One potential explanation for this observation is the presence of live and active cultures in yogurt. Yogurt contains the starter cultures S. thermophilus and the L. delbrueckii subspecies bulgaricus which are thought to contribute to heath. Other Bifidobacterium and Lactobacillus strains are sometimes added as probiotics, which are live microorganisms that when consumed in adequate amounts confer a health benefit in the host [50]. It has been hypothesized that the either the starter cultures, the probiotics, or the combination can beneficially impact the gut microbiota composition and function [6,51]. Thus, the observed link between yogurt consumption and better body composition could be driven by changes in the microbiota that are impacting energy metabolism. Since the present analysis did not distinguish between those yogurts that contain just the starter cultures and those with added probiotics, nor did it compare yogurts with live cultures to pasteurized products, additional work is needed to further elucidate the role of fermentation-associated microbes on weight and body composition. A healthier dietary pattern (higher intakes of fruits and vegetables, whole grain, and dairy) as observed in our analysis for yogurt consumers, along with potentially other lifestyle differences (e.g., more physical activity among yogurt consumers), could help explain the current findings of a lower body weight, BMI, and waist circumference and lowered risk for obesity. The results of this study are congruent with those from other cross-section studies that have shown that yogurt consumption was associated with a lower BMI, lower body weight/weight gain, and smaller waist circumference [21,22,25]. This finding may have important health and economic implications as more than one third of US adults are obese [52], and obesity is associated with several health risks [53] with annual medical costs amounting to $\$ 147$ billion [54].

The regular consumption of added sugars from certain products has been associated with an increased risk of obesity [55-57]. The DGA recommends limiting intake of added sugars to less than $10 \%$ of total daily calories as part of a healthy diet [30]. More recently, the 2020 Dietary Guidelines Advisory Committee recommended that the intake of added sugars be lowered to $6 \%$ of total calories given their impact on health [58]. Flavored yogurts have the same nutrition profile as plain yogurts. The data presented herein showed that the intake of added sugars was nearly identical between non-consumers and consumers in both children and adults (Table 2), indicating that yogurt consumption was not linked to higher intakes of added sugars in this cohort. This study examined the short-term impact of yogurt intake on nutrient adequacy and body composition and did not distinguish between flavored and plain yogurts. Thus, additional work is needed to more fully understand the link between long term flavored yogurt intake and health.

The strengths of this study include the use of a large nationally representative sample achieved through combining several sets of NHANES data releases and the use of numerous covariates to adjust data to remove potential confounding. A major limitation of this study is the use of a cross-sectional study design, which cannot be used to determine cause and effect. The dietary intake data were self-reported recalls relying on memory and are potentially subject to reporting bias. Finally, while we accounted for a number of covariates in our statistical models, residual confounding cannot be ruled out.

\section{Conclusions}

In conclusion, the results showed that yogurt consumption was associated with higher nutrient intake, better nutrient adequacy, and better diet quality in both children and adults. Additionally, yogurt consumption was linked to a lower body weight and related parameters in adults. Long-term 
randomized controlled trials are needed to further examine the effects of yogurt consumption on body weight. Encouraging yogurt consumption may be an effective strategy for improving intakes and adequacy of certain nutrients and achieving a healthier dietary pattern.

Supplementary Materials: The following are available online at http://www.mdpi.com/2072-6643/12/11/3435/s1, Table S1: Demographics associated with yogurt consumption in children and adults (NHANES 2001-2016, gender combined data).

Author Contributions: The authors' responsibilities were as follows: C.J.C.: Project conception, designed research, developed overall research plan, and participated in revising the manuscript; S.A.: Participated in interpretation of the data, prepared the first draft of the manuscript, and participated in revising the manuscript; V.L.F.III: Designed research, developed overall research plan, analyzed data, performed statistical analysis, and participated in interpretation of the data and revising the manuscript; All authors have read and agreed to the published version of the manuscript.

Funding: The study and the writing of the manuscript were funded by the National Dairy Council, Rosemont, IL, USA.

Conflicts of Interest: C.J.C is an employee of the National Dairy Council, Rosemont, IL, USA; S.A. is a Principal of NutriScience; L.L.C. performs nutrition science consulting for various food and beverage companies and related entities; and V.L.F. is the Senior Vice President of Nutrition Impact.

\section{References}

1. Hutkins, R.W. Microbiology and Technology of Fermented Foods, 2nd ed.; Wiley: Hoboken, NJ, USA, 2018.

2. FDA. Yogurt. 21 CFR 131.200, Code of Federal Regulations; US Department of Health and Human Services: Washington, DC, USA, 2013.

3. USDA-ERS. Dairy Data. Available online: https://www.ers.usda.gov/data-products/dairy-data.aspx (accessed on 17 August 2020).

4. Nielsen, S.J.; Ogden, C. Trends in yogurt consumption, US adults, 1999-2012. FASEB J. 2015, 29, 587.17.

5. USDA Food Data Central Database. Available online: https://fdc.nal.usda.gov/ (accessed on 20 March 2020).

6. Kok, C.R.; Hutkins, R. Yogurt and other fermented foods as sources of health-promoting bacteria. Nutr. Rev. 2018, 76, 4-15. [CrossRef] [PubMed]

7. Savaiano, D.A.; Hutkins, R.W. Yogurt, cultured fermented milk, and health: A systematic review. Nutr. Rev. 2020. [CrossRef] [PubMed]

8. Fernandez, M.A.; Panahi, S.; Daniel, N.; Tremblay, A.; Marette, A. Yogurt and cardiometabolic diseases: A critical review of potential mechanisms. Adv. Nutr. 2017, 8, 812-829. [CrossRef] [PubMed]

9. Astrup, A. Yogurt and dairy product consumption to prevent cardiometabolic diseases: Epidemiologic and experimental studies. Am. J. Clin. Nutr. 2014, 99, 1235S-1242S. [CrossRef]

10. Gijsbers, L.; Ding, E.L.; Malik, V.S.; de Goede, J.; Geleijnse, J.M.; Soedamah-Muthu, S.S. Consumption of dairy foods and diabetes incidence: A dose-response meta-analysis of observational studies. Am. J. Clin. Nutr. 2016, 103, 1111-1124. [CrossRef]

11. Chen, M.; Sun, Q.; Giovannucci, E.; Mozaffarian, D.; Manson, J.E.; Willett, W.C.; Hu, F.B. Dairy consumption and risk of type 2 diabetes: 3 cohorts of US adults and an updated meta-analysis. BMC Med. 2014, 12, 215. [CrossRef]

12. Wu, L.; Sun, D. Consumption of yogurt and the incident risk of cardiovascular disease: A meta-analysis of nine cohort studies. Nutrients 2017, 9, 315. [CrossRef] [PubMed]

13. PREDIMED Investigators. Consumption of yogurt, low-fat milk, and other low-fat dairy products is associated with lower risk of metabolic syndrome incidence in an elderly Mediterranean population. J. Nutr. 2015, 145, 2308-2316. [CrossRef]

14. Farvid, M.S.; Malekshah, A.F.; Pourshams, A.; Poustchi, H.; Sepanlou, S.G.; Sharafkhah, M.; Khoshnia, M.; Farvid, M.; Abnet, C.C.; Kamangar, F.; et al. Dairy food intake and all-cause, cardiovascular disease, and cancer mortality: The Golestan cohort study. Am. J. Epidemiol. 2017, 185, 697-711. [CrossRef]

15. Buendia, J.R.; Li, Y.; Hu, F.B.; Cabral, H.J.; Bradlee, M.L.; Quatromoni, P.A.; Singer, M.R.; Curhan, G.C.; Moore, L.L. Long-Term yogurt consumption and risk of incident hypertension in adults. J. Hypertens. 2018, 36, 1671-1679. [CrossRef] 
16. Wang, H.; Fox, C.S.; Troy, L.M.; Mckeown, N.M.; Jacques, P.F. Longitudinal association of dairy consumption with the changes in blood pressure and the risk of incident hypertension: The Framingham Heart Study. Br. J. Nutr. 2015, 114, 1887-1899. [CrossRef]

17. Trichia, E.; Luben, R.; Khaw, K.T.; Wareham, N.J.; Imamura, F.; Forouhi, N.G. The associations of longitudinal changes in consumption of total and types of dairy products and markers of metabolic risk and adiposity: Findings from the European Investigation into Cancer and Nutrition (EPIC)-Norfolk study, United Kingdom. Am. J. Clin. Nutr. 2020, 111, 1018-1026. [CrossRef]

18. Mozaffarian, D.; Hao, T.; Rimm, E.B.; Willett, W.C.; Hu, F.B. Changes in diet and lifestyle and long-term weight gain in women and men. New Eng. J. Med. 2011, 364, 2392-2404. [CrossRef]

19. Eales, J.; Lenoir-Wijnkoop, I.; King, S.; Wood, H.; Kok, F.J.; Shamir, R.; Prentice, A.; Edwards, M.; Glanville, J.; Atkinson, R.L. Is consuming yoghurt associated with weight management outcomes? Results from a systematic review. Int. J. Obes. 2016, 40, 731-746. [CrossRef]

20. Wang, H.; Troy, L.M.; Rogers, G.T.; Fox, C.S.; McKeown, N.M.; Meigs, J.B.; Jacques, P.F. Longitudinal association between dairy consumption and changes of body weight and waist circumference: The Framingham Heart Study. Int. J. Obes. 2014, 38, 299-305. [CrossRef] [PubMed]

21. Hobbs, D.A.; Givens, D.I.; Lovegrove, J.A. Yogurt consumption is associated with higher nutrient intake, diet quality and favourable metabolic profile in children: A cross-sectional analysis using data from years 1-4 of the National diet and Nutrition Survey, UK. Eur. J. Nutr. 2019, 58, 409-422. [CrossRef]

22. Vatanparast, H.; Islam, N.; Patil, R.P.; Shamloo, A.; Keshavarz, P.; Smith, J.; Whiting, S. Consumption of yogurt in Canada and its contribution to nutrient intake and diet quality among Canadians. Nutrients 2019, 11, 1203. [CrossRef]

23. Wang, H.; Livingston, K.A.; Fox, C.S.; Meigs, J.B.; Jacques, P.F. Yogurt consumption is associated with better diet quality and metabolic profile in American men and women. Nutr. Res. 2013, 33, 18-26. [CrossRef] [PubMed]

24. Zhu, Y.; Wang, H.; Hollis, J.H.; Jacques, P.F. The associations between yogurt consumption, diet quality, and metabolic profiles in children in the USA. Eur. J. Nutr. 2015, 54, 543-550. [CrossRef]

25. Keast, D.R.; Hill Gallant, K.M.; Albertson, A.M.; Gugger, C.K.; Holschuh, N.M. Associations between yogurt, dairy, calcium, and vitamin D intake and obesity among U.S. children aged 8-18 years: NHANES, 2005-2008. Nutrients 2015, 7, 1577-1593. [CrossRef]

26. Centers for Disease Control and Prevention (CDC); National Center for Health Statistics. National Health and Nutrition Examination Survey. Hyattsville, M.D.: National Center for Health Statistics. Available online: https://www.cdc.gov/nchs/nhanes/index.htm (accessed on 25 March 2020).

27. National Center for Health Statistics. Available online: http://www.cdc.gov/nchs/nhanes/ (accessed on 16 September 2020).

28. Raper, N.; Perloff, B.; Ingwersen, L.; Steinfeldt, L.; Anand, J. An overview of USDA's dietary intake data system. J. Food Comp. Anal. 2004, 17, 545-555. [CrossRef]

29. U.S. Department of Agriculture, Agricultural Research Service. 2018; USDA Food and Nutrient Database for Dietary Studies. Food Surveys Research Group Home Page. Available online: http://www.ars.usda.gov/nea/ bhnrc/fsrg (accessed on 25 March 2020).

30. U.S. Department of Health and Human Services; U.S. Department of Agriculture. 2015-2020 Dietary Guidelines for Americans, 8th ed.; December 2015. Available online: http://health.gov/dietaryguidelines/2015/guidelines/ (accessed on 7 July 2020).

31. Krebs-Smith, S.M.; Pannucci, T.E.; Subar, A.F.; Kirkpatrick, S.I.; Lerman, J.L.; Tooze, J.A.; Wilson, M.M.; Reedy, J. Update of the Healthy Eating Index: HEI-2015. J. Acad. Nutr. Diet. 2018, 118, 1591-1602. [CrossRef]

32. U.S. Department of Agriculture, Agricultural Research Service. USDA Food Patterns Equivalent Database. Available online: https://www.ars.usda.gov/northeast-area/beltsville-md-bhnrc/beltsville-human-nutritionresearch-center/food-surveys-research-group/docs/fped-overview/ (accessed on 25 March 2020).

33. USDA. Choose My Plate. Available online: https://www.choosemyplate.gov (accessed on 25 March 2020).

34. Kuczmarski, R.J.; Ogden, C.L.; Guo, S.S.; Grummer-Strawn, L.M.; Flegal, K.M.; Mei, Z.; Wei, R.; Curtin, L.R.; Roche, A.F.; Johnson, C.L. 2000 CDC Growth Charts for the United States: Methods and Development; Department of Health and Human Services, Centers for Disease Control and Prevention, National Center for Health Statistics: Rockville, MD, USA, 2002; Volume 11, pp. 1-190. 
35. Expert Panel on the Identification, Evaluation, and Treatment of Overweight in Adults. Clinical Guidelines on the Identification, Evaluation, and Treatment of Overweight and Obesity in Adults: Executive Summary; National Institutes of Health, National Heart, Lung, and Blood Institute: Bethesda, MD, USA, 1998; Volume 68, pp. 899-917. [CrossRef]

36. Tooze, J.A.; Kipnis, V.; Buckman, D.W.; Carroll, R.J.; Freedman, L.S.; Guenther, P.M.; Krebs-Smith, S.M.; Subar, A.F.; Dodd, K.W. A mixed-effects model approach for estimating the distribution of usual intake of nutrients: The NCI method. Stat. Med. 2010, 29, 2857-2868. [CrossRef]

37. Dietary Guidelines Advisory Committee. Scientific Report of the 2015 Dietary Guidelines Advisory Committee: Advisory Report to the Secretary of Health and Human Services and the Secretary of Agriculture; U.S. Department of Agriculture, Agricultural Research Service: Washington, DC, USA. Available online: https://www.dietaryguidelines.gov/sites/default/files/2019-05/Scientific-Report-of-the-2015-DietaryGuidelines-Advisory-Committee.pdf (accessed on 7 July 2020).

38. Muehlhoff, E.; Bennett, A.; Mcmahon, D. Milk and Dairy Products in Human Nutrition; Food and Agriculture Organization of the United Nations: Rome, Italy, 2013.

39. Pfeuffer, M.; Watzl, B. Nutrition and health aspects of milk and dairy products and their ingredients. Ernahr. Umsch. 2018, 65, 22-33.e14-e17. [CrossRef]

40. O'Neil, C.E.; Nicklas, T.A.; Fulgoni, V.L., III. Food sources of energy and nutrients of public health concern and nutrients to limit with a focus on milk and other dairy foods in children 2 to 18 years of age: National health and nutrition examination survey, 2011-2014. Nutrients 2018, 10, 1050. [CrossRef]

41. O'Neil, C.E.; Keast, D.R.; Fulgoni, V.L.; Nicklas, T.A. Food sources of energy and nutrients among adults in the US: NHANES 2003-2006. Nutrients 2012, 4, 2097-2120. [CrossRef]

42. Hiza, H.A.; Casavale, K.O.; Guenther, P.M.; Davis, C.A. Diet quality of Americans differs by age, sex, race/ethnicity, income, and education level. J. Acad. Nutr. Diet. 2013, 113, 297-306. [CrossRef]

43. Reedy, J.; Krebs-Smith, S.M.; Bosire, C. Evaluating the food environment: Application of the Healthy Eating Index-2005. Am. J. Prev. Med. 2010, 38, 465-471. [CrossRef]

44. USDA-CNPP. Nutrition Insight 41. Diet Quality of Older Americans in 1994-96 and 2001-02 as Measured by the Healthy Eating Index-2005; USDA/CNPP: Alexandria, VA, USA, 2008.

45. Fulgoni, V.L.; Keast, D.R.; Drewnowski, A. Development and validation of the nutrient-rich foods index: A tool to measure nutritional quality of foods. J. Nutr. 2009, 139, 1549-1554. [CrossRef]

46. Nicklas, T.A.; O'Neil, C.E.; Fulgoni, V.L. Diet quality is inversely related to cardiovascular risk factors in adults. J. Nutr. 2012, 142, 2112-2118. [CrossRef]

47. Chiuve, S.E.; Fung, T.T.; Rimm, E.B.; Hu, F.B.; McCullough, M.L.; Wang, M.; Stampfer, M.J.; Willett, W.C. Alternative dietary indices both strongly predict risk of chronic disease. J. Nutr. 2012, 142, 1009-1018. [CrossRef] [PubMed]

48. Reedy, J.; Mitrou, P.N.; Krebs-Smith, S.M.; Wirfalt, E.; Flood, A.; Kipnis, V.; Leitzmann, M.; Mouw, T.; Hollenbeck, A.; Schatzkin, A.; et al. Index-based dietary patterns and risk of colorectal cancer: The NIH-AARP diet and health study. Am. J. Epidemiol. 2008, 168, 38-48. [CrossRef]

49. O'Neil, C.E.; Nicklas, T.A.; Rampersaud, G.C.; Fulgoni, V.L. One hundred percent orange juice consumption is associated with better diet quality, improved nutrient adequacy, and no increased risk for overweight/obesity in children. Nutr. Res. 2011, 31, 673-682. [CrossRef]

50. Hill, C.; Guarner, F.; Reid, G.; Gibson, G.R.; Merenstein, D.J.; Pot, B.; Morelli, L.; Canani, R.B.; Flint, H.J.; Salminen, S.; et al. Expert consensus document. The international scientific association for probiotics and prebiotics consensus statement on the scope and appropriate use of the term probiotic. Nat. Rev. Gastroenterol. Hepatol. 2014, 11, 506-514. [CrossRef]

51. Marco, M.L.; Heeney, D.; Binda, S.; Cifelli, C.J.; Cotter, P.D.; Foligne, B.; Ganzle, M.; Kort, R.; Pasin, G.; Pihlanto, A.; et al. Health benefits of fermented foods: Microbiota and beyond. Curr. Opin. Biotechnol. 2017, 44, 94-102. [CrossRef] [PubMed]

52. Ogden, C.L.; Carroll, M.D.; Kit, B.K.; Flegal, K.M. Prevalence of childhood and adult obesity in the United States, 2011-2012. JAMA 2014, 311, 806-814. [CrossRef]

53. U.S. Department of Health and Human Services, Office of the Surgeon General. The Surgeon General's Vision for a Healthy and Fit Nation; U.S. Department of Health and Human Services, Office of the Surgeon General: Rockville, MD, USA, 2010. 
54. Finkelstein, E.A.; Trogdon, J.G.; Cohen, J.W.; Dietz, W. Annual medical spending attributable to obesity: Payer-and service-specific estimates. Health. Aff. 2009, 28, w822-w831. [CrossRef]

55. Olsen, N.J.; Heitmann, B.L. Intake of calorically sweetened beverages and obesity. Obes. Rev. 2009, 10, 68-75. [CrossRef]

56. Malik, V.S.; Schulze, M.B.; Hu, F.B. Intake of sugar-sweetened beverages and weight gain: A systematic review. Am. J. Clin. Nutr. 2006, 84, 274-288. [CrossRef]

57. Malik, V.S.; Popkin, B.M.; Bray, G.A.; Despres, J.P.; Hu, F.B. Sugar-sweetened beverages, obesity, type 2 diabetes mellitus, and cardiovascular disease risk. Circulation 2010, 121, 1356-1364. [CrossRef]

58. Dietary Guidelines Advisory Committee. Scientific Report of the 2020 Dietary Guidelines Advisory Committee: Advisory Report to the Secretary of Agriculture and the Secretary of Health and Human Services; U.S. Department of Agriculture, Agricultural Research Service: Washington, DC, USA. Available online: https://www. dietaryguidelines.gov/2020-advisory-committee-report (accessed on 16 September 2020).

Publisher's Note: MDPI stays neutral with regard to jurisdictional claims in published maps and institutional affiliations.

(C) 2020 by the authors. Licensee MDPI, Basel, Switzerland. This article is an open access article distributed under the terms and conditions of the Creative Commons Attribution (CC BY) license (http://creativecommons.org/licenses/by/4.0/). 